(1)

CrossMark

\title{
COVID-19 and smoking: is nicotine the hidden link?
}

\author{
To the Editor:
}

LEUNG et al. [1] have recently published, in the European Respiratory Journal, a paper on the expression of angiotensin-converting enzyme II (ACE-2) in the small airway epithelia of smokers and COPD patients, discussing its effects on the risk of severe coronavirus disease 2019 (COVID-19). The authors found an increased expression of the ACE-2 gene in the airways of subjects with COPD and in current smokers. Indeed, a recent systematic review reporting data on the smoking habits of patients infected with severe acute respiratory syndrome coronavirus 2 (SARS-CoV-2), concluded that smoking may be associated with a negative progression of the disease and with the adverse outcome [2]. These conclusions were challenged in a correspondence by CAI [3] on the basis that a reliable mechanism explaining this association was missing. The need for these results to be supported by additional studies is quite clear, but we believe that a robust mechanistic explanation exists. Nicotine has a known influence on the homeostasis of the reninangiotensin system (RAS) up-regulating the angiotensin-converting enzyme (ACE)/angiotensin (ANG)-II/ ANG II type 1 receptor axis, and down-regulating the compensatory ACE-2/ANG-(1-7)/Mas receptor axis, contributing in turn to the development of cardiovascular and pulmonary diseases [4]. Different airway cells, such as bronchial epithelial cells, type II alveolar epithelial cells and interstitial lung fibroblasts, express nicotinic acetylcholine receptors (nAChR), specifically the $\alpha 7$ subtype [5]. All these cells express components of the RAS [4]. In addition, nicotine increases the expression and/or activity of ACE in the lung [4], an increase which has been found also in the serum of smokers, and that required at least $20 \mathrm{~min}$ to return to control level [4]. ACE-2 serves as a physiologically relevant cellular entry receptor for SARS-CoV, for the human respiratory coronavirus NL63, and probably for SARS-CoV-2 [6]. ACE binds the SARS-CoV-2 S protein, and through its tissutal expression mediates the localisation and the efficiency of the infection [6]. Moreover, nicotine induces the epithelial-mesenchymal transition (EMT) [5, 7], a mechanism sufficient to allow "normal" differentiated cells to acquire the stem cell-like characteristics and properties. We planned experiments on human bronchial epithelial cells (HBEpC), obtained from Cell Applications Inc. (www.cellapplications.com/product number 502K-05a). Cells were maintained as adherent monolayer in complete bronchial/tracheal epithelial cell growth medium (www.cellapplications. com/product) at $37^{\circ} \mathrm{C}$ in $95 \%$ air $/ 5 \% \mathrm{CO}_{2}$, seeded at an initial density of $7.5 \times 10^{4} \mathrm{cells} \cdot \mathrm{cm}^{-2}$, and sub-cultured with a $0.25 \%$ trypsin-1 mM EDTA solution (Sigma-Aldrich, Milan, Italy) when cultures reached $80 \%$ confluence. HBEpC are derived from the surface epithelium of normal human bronchi non-diseased (i.e. asthma, COPD or type 2 diabetes). The morphology is consistent with epithelial origin, and is positive for epithelial cell marker cytokeratin 18. Semi-confluent HBEpC at fourth passage $\left(7.5 \times 10^{4}\right.$ cells $\left.\cdot \mathrm{cm}^{-2}\right)$ were treated: 1$)$ for $1 \mathrm{~h}$ with zero or $1.0 \times 10^{-7} \mathrm{M}$ nicotine (Sigma-Aldrich, Milan, Italy) dissolved in saline in complete medium; 2) with $1.0 \times 10^{-6} \mathrm{M} \alpha$-Bungarotoxin ( $\alpha$-BTX; Sigma-Aldrich, Milan, Italy) dissolved in saline, in the continued presence of nicotine at zero or $1.0 \times 10^{-7} \mathrm{M}$ for $1 \mathrm{~h}$; 3) treated continuously with nicotine for additional passages, 1 passage every $48 \mathrm{~h}$ for a total of 16 passages. We showed, for the first time, that nicotine at $1 \times 10^{-7} \mathrm{M}$ (the concentration present on the alveolar lining fluids after one cigarette is in the range $6 \times 10^{-6}$ to $6 \times 10^{-5} \mathrm{M}$ [5]) is able to increase ACE-2 (figure 1a) in HBEpC. Treatment with nicotine induces phospho-S6 ribosomal protein (Ser235/ 236), Akt1, phospho-Akt (Ser473), phospho-Akt (Thr308) and phospho-p44/42 MAPK (Thr202/Tyr204) (figure $1 \mathrm{~b}$ ). To verify the hypothesis that ACE-2 is induced by nicotine through $\alpha 7-\mathrm{nAChR}, \mathrm{HBEpC}$, at fourth passage, in the exponential growth phase, plated at a density of $1 \times 10^{6}$ cells $\cdot \mathrm{mL}^{-1}$, were incubated with $\alpha 7$-nAChR siRNA $(0.1 \mu \mathrm{g})$ diluted in $100 \mu \mathrm{L}$ of siRNA transfection medium. Transfection was performed as described by Li et al. [8], who transfected, successfully, HBE16 human airway epithelial cell line (unaffected cells). A clone of transfected HBEpC that did not express $\alpha 7$-nAChR proteins, also after

@ERSpublications

Nicotine via alpha7-nicotinic receptor induces ACE-2 overexpression in human bronchial epithelial cells (HBEpC) https://bit.ly/3eJ5b35

Cite this article as: Russo P, Bonassi S, Giacconi R, et al. COVID-19 and smoking: is nicotine the hidden link? Eur Respir J 2020; 55: 2001116 [https://doi.org/10.1183/13993003.01116-2020]. 


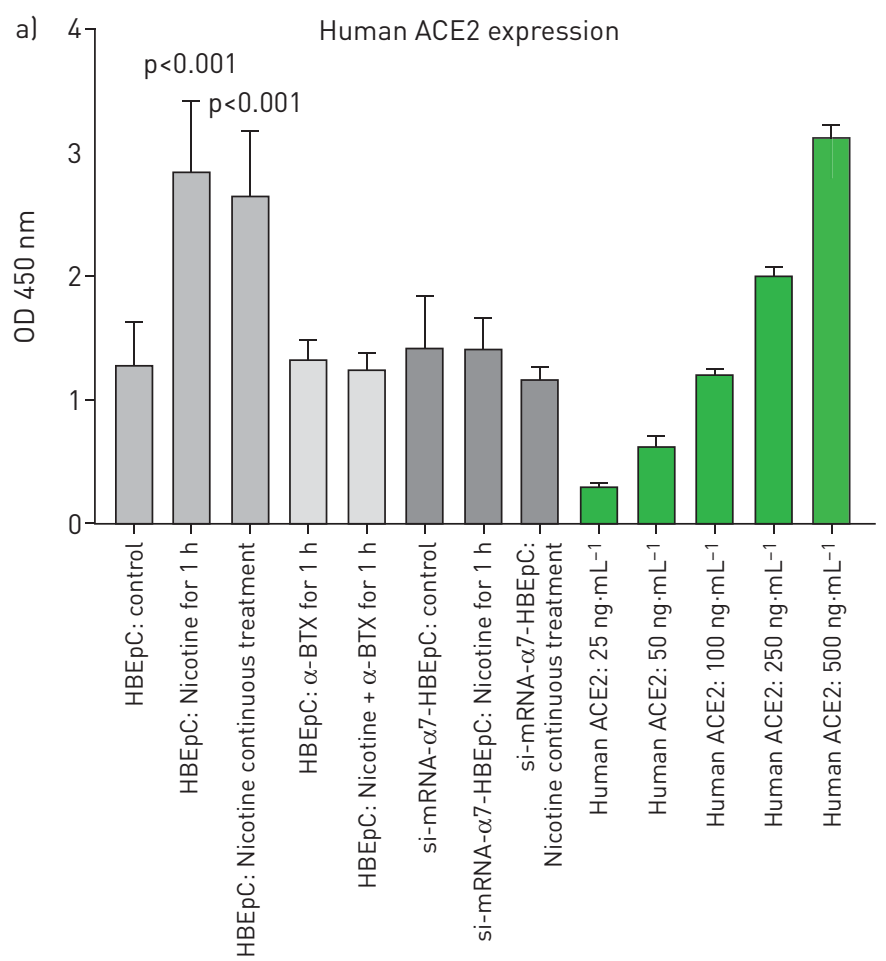

c)
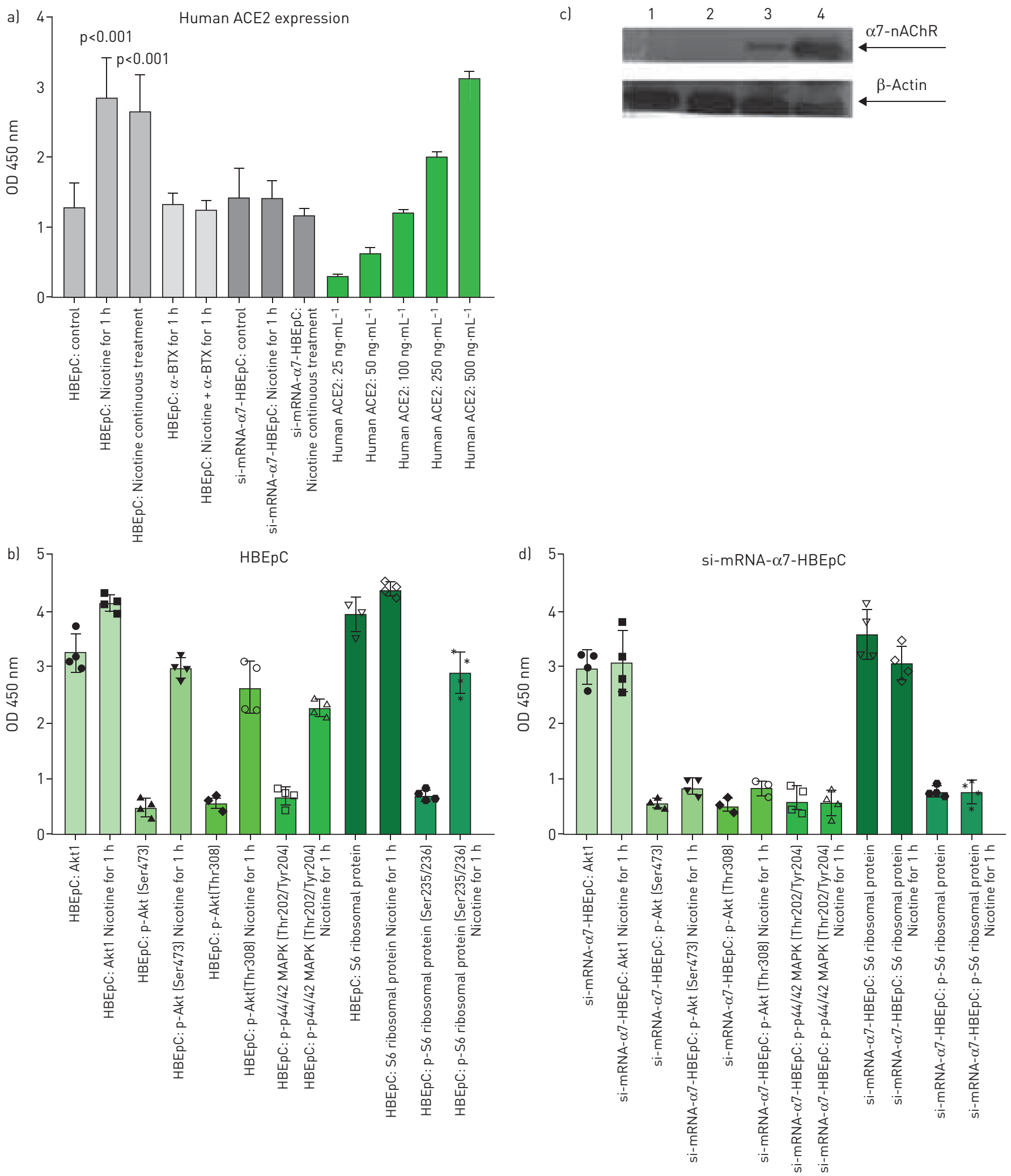

FIGURE 1 Effect of nicotine on human bronchial epithelial cells (HBEpC) or si-mRNA- $\alpha 7-H B E p C$. a) Angiotensin-converting enzyme II (ACE-2) detection. ACE-2 was measured with human ACE-2 ELISA kit ab235649 (www.abcam.com/human-ace2-elisa-kit-ab235649.html) according to the manufacturer's instructions. Data are mean \pm SEM; $p$-vaule was evaluated using t-test. The green plots are the human ACE-2 standard. Experiments were performed twice in triplicate. b) Induction of phospho-S6 ribosomal protein (Ser235/236), Akt1, phospho-Akt (Ser473), phospho-Akt (Thr308) 
and phospho-p44/42 MAPK (Thr202/Tyr204) in HBEpC. Data were obtained using PathScan® cell growth Multi-target Sandwich ELISA kit n.7239 (Cell Signaling) PathScan ${ }^{\circledR}$ Cell Growth Multi-Target Sandwich ELISA Kit is a solid phase sandwich ELISA that combines the reagents necessary to detect endogenous levels of S6 ribosomal protein, phospho-S6 ribosomal protein (Ser235/236), Akt1, phospho-Akt (Ser473), phospho-Akt (Thr308) and phospho-p44/42 MAPK (Thr202/Tyr204). Data are mean士SEM; p-value was evaluated using t-test. Experiments were performed twice in duplicate. c) $\alpha 7-n A C h R$ protein detection. Western blotting was performed as described previously [11]. Human $\alpha 7-n A c h R$ antibody NBP1-49348 was purchased from Novus Biologicals (www.novusbio.com). 1-2 si-mRNA- $\alpha 7-$ HBEpC treated with zero (lane 1 ) or $1.0 \times 10^{-7} \mathrm{M}$ nicotine (lane 2 ) for $1 \mathrm{~h} .3-4 \mathrm{HBEpC}$ treated with zero (lane 3) or $1.0 \times 10^{-7} \mathrm{M}$ nicotine (lane 4 ) for $1 \mathrm{~h}$. Experiments were performed twice. $\mathrm{d}$ ) as in panel b, but treated cells are si-mRNA- $\alpha 7-\mathrm{HBEpC}$.

treatment with nicotine (figure 1c), and is not able to induce phospho-S6 ribosomal protein (Ser235/236), Akt1, phospho-Akt (Ser473), phospho-Akt (Thr308) and phospho-p44/42 MAPK (Thr202/Tyr204) after nicotine treatment (figure 1d), was selected for further experiments. Nicotine did not induce ACE-2 in this clone (si-mRNA- $\alpha 7-\mathrm{HBEpC}$ ) (figure 1a). This observation supports the hypothesis that ACE-2 increase is specifically mediated by $\alpha 7-\mathrm{nAChR}$. Moreover, when HBEpC were incubated simultaneously with nicotine and $\alpha$-BTX, an $\alpha 7$ nicotine antagonist [9], no induction of ACE-2 was observed (figure 1d). Importantly, treatment with nicotine, $\alpha$-BTX or with the combination is not cytotoxic (data not shown). On these bases, we suggest that smoking may promote cellular uptake mechanisms of SARS-CoV-2 through $\alpha 7$-nAChR signalling. A possible $\alpha 7$-nAChR down-stream mechanism may be the induction of phospho-Akt and phospho-p44/42 MAPK. This mechanism was hypothesised, partially, by OLDs and KABBANI [10] on their schematic model explaining how nicotine exposure increases the risk of SARS-CoV-2 entry into lung cells. $\alpha 7-n A C h R$ is present both in neuronal and non-neuronal cells (i.e. lung, endothelial, lymphocyte); consequently, smoking may impact COVID-19 pathophysiology and clinical outcome in several organ systems, including the brain.

Patrizia Russo $o^{1,2}$, Stefano Bonassi $^{1,2}$, Robertina Giacconi ${ }^{3}$, Marco Malavolta $\oplus^{3}$, Carlo Tomino ${ }^{4}$ and Fabrizio Maggi ${ }^{5,6}$

${ }^{1}$ Clinical and Molecular Epidemiology, IRCSS San Raffaele Pisana, Rome, Italy. ${ }^{2}$ Dept of Human Sciences and Quality of Life Promotion, San Raffaele University, Rome, Italy. ${ }^{3}$ Advanced Technology Center for Aging Research, Scientific Technological Area, Italian National Institute of Health and Science on Aging (INRCA), Ancona, Italy. ${ }^{4}$ Scientific Direction, IRCSS San Raffaele Pisana, Rome, Italy. ${ }^{5}$ Dept of Translational Research, University of Pisa, Pisa, Italy. ${ }^{6}$ Virology Division, Pisa University Hospital, Pisa, Italy.

Correspondence: Patrizia Russo, Clinical and Molecular Epidemiology, IRCSS San Raffaele Pisana, Via di Val Cannuta, 247, I-00166 Rome, Italy. E-mail: patrizia_russo@hotmail.it

Received: 10 April 2020 | Accepted after revision: 16 April 2020

Conflict of interest: None declared.

\section{References}

1 Leung JM, Yang CX, Tam A, et al. ACE-2 expression in the small airway epithelia of smokers and COPD patients: implications for COVID-19. Eur Respir J 2020; 55: 2000688.

2 Vardavas CI, Nikitara K. COVID-19 and smoking: a systematic review of the evidence. Tob Induc Dis 2020; $18: 20$.

3 Cai H. Sex difference and smoking predisposition in patients with COVID-19. Lancet Respir Med 2020; 8: e20.

4 Oakes JM, Fuchs RM, Gardner JD, et al. Nicotine and the renin-angiotensin system. Am J Physiol Regul Integr Comp Physiol 2020; 315: R895-R906.

5 Cardinale A, Nastrucci C, Cesario A, et al. Nicotine: specific role in angiogenesis, proliferation and apoptosis. Crit Rev Toxicol 2012; 42: 68-89.

6 Zhou P, Yang XL, Wang XG, et al. A pneumonia outbreak associated with a new coronavirus of probable bat origin. Nature 2020; 579: 270-273.

7 Santoro A, Tomino C, Prinzi G, et al. Tobacco smoking: risk to develop addiction, chronic obstructive pulmonary disease, and lung cancer. Recent Pat Anticancer Drug Discov 2019; 14: 39-52.

8 Li Q, Zhou X, Kolosov VP, et al. The expression and pharmacological characterization of nicotinic acetylcholine receptor subunits in HBE16 airway epithelial cells. Cell Biochem Biophys 2012; 62: 421-431.

9 Wang YY, Liu Y, Ni XY, et al. Nicotine promotes cell proliferation and induces resistance to cisplatin by $\alpha 7$ nicotinic acetylcholine receptor-mediated activation in Raw264.7 and El4 cells. Oncol Rep 2014; 31: 1480-1488.

10 Olds JL, Kabbani N. Is nicotine exposure linked to cardiopulmonary vulnerability to COVID-19 in the general population? FEBS J 2020; in press [https://doi.org/10.1111/febs.15303].

11 Trombino S, Cesaro A, Margaritora S, et al. Alpha7-nicotinic acetylcholine receptors affect growth regulation of human mesothelioma cells: role of mitogen-activated protein kinase pathway. Cancer Res 2004; 64: 135-145. 


\section{(d) \\ CrossMark}

\section{COVID-19 and nicotine as a mediator of ACE-2}

From the authors:

We recently reported that current smokers and those with COPD had higher airway epithelial cell expression of the angiotensin-converting enzyme II (ACE-2) viral entry receptor [1]. We thus read with great interest the work of P. Russo and co-workers, which proposes a mechanism for this finding, namely that this upregulation is mediated by nicotine exposure specifically through the $\alpha 7$ subtype of nicotine acetylcholine receptors ( $\alpha 7-\mathrm{nAChR})$. While exposure to increasing concentrations of nicotine caused epithelial cells to increase ACE-2 levels, subsequent gene silencing of $\alpha 7-n A C h R$ appeared to significantly dampen this response. A secondary transcriptome sequencing analysis of our cohort (consisting of 42 subjects who underwent bronchoscopy for epithelial cell brushings [1]) reveals evidence in support of this hypothesis. We found that airway epithelial cell expression of CHRNA7, encoding $\alpha 7-n A C h R$, was significantly correlated with the expression of ACE2 (Pearson $\mathrm{r}=0.54, \mathrm{p}=2.31 \times 10^{-8}$ ) (figure 1 ). There was significantly higher CHRNA7 expression in those with COPD ( $2.75 \pm 0.73$ versus $2.14 \pm 0.43$ in those without COPD; $\left.\mathrm{p}=1.47 \times 10^{-4}\right)$, with a trend towards higher expression in current smokers compared to former and never smokers $(2.86 \pm 0.92$ in current smokers, $2.35 \pm 0.57$ in former smokers, and $2.27 \pm 0.45$ in never smokers; $\mathrm{p}=6.16 \times 10^{-2}$ ). CHRNA7 was also negatively correlated with forced expiratory volume in $1 \mathrm{~s}$ percent predicted (Pearson $\mathrm{r}=-0.37, \mathrm{p}=2.83 \times 10^{-4}$ ). Interestingly, CHRNA7 was positively if weakly correlated with body mass index (Pearson $\mathrm{r}=0.14, \mathrm{p}=6.31 \times 10^{-3}$ ), raising the intriguing possibility that nicotine receptor mediation of ACE-2 may also be related to why obese individuals have made up a considerable proportion of coronavirus disease 2019 (COVID-19) cases [2].

FIGURE 1 Transcriptome profiles generated through RNA-Seq of airway epithelial cells demonstrated a significant positive correlation between ACE2 and CHRNA7 expression.

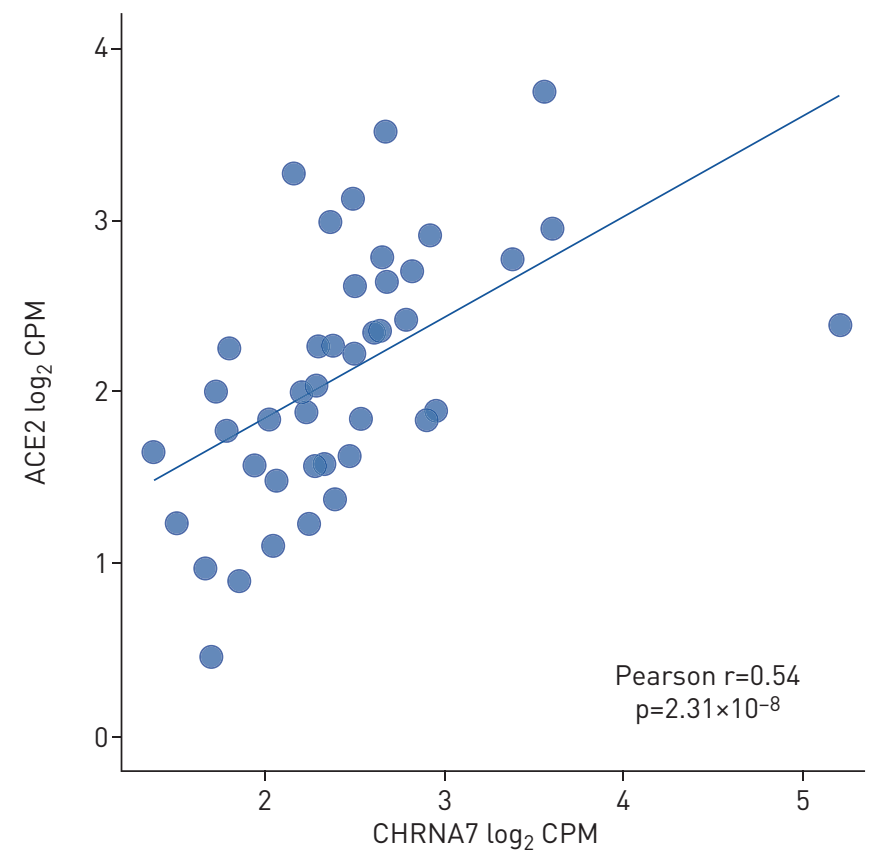

Together, these data further help to characterise the connections between airway epithelial ACE-2, and $\alpha 7-\mathrm{nAChR}$, and the unique vulnerability of patients with COPD to severe COVID-19. $\alpha 7-\mathrm{nAChR}$ 's

Cite this article as: Leung JM, Yang CX, Sin DD. COVID-19 and nicotine as a mediator of ACE-2 Eur Respir J 2020; 55: 2001261 [https://doi.org/10.1183/13993003.01261-2020]. 
widespread abundance in the human body, from neuronal tissue to immune cells to the lung and digestive tract, and its various roles in diseases such as schizophrenia [3], Alzheimer's disease [4] and Parkinson's disease [5] has meant that considerable work has already been done to target $\alpha 7-\mathrm{nAChR}$ as a therapeutic modality. As an example, $\alpha 7-n A C h R$ antagonists for the purpose of smoking cessation have long been proposed [6] and the idea of potentially repurposing these compounds for a pandemic with few therapeutic options currently available is certainly appealing. Whether $\alpha 7-n A C h R$-selective antagonists, such as methyllycaconitine [7] and $\alpha$-conotoxin [8], can meaningfully alter ACE-2 expression to prevent severe acute respiratory syndrome coronavirus 2 entry into the airway epithelium seems the next logical investigation in our furious pursuit for better therapeutics.

Janice M. Leung ${ }^{1,2}$, Chen Xi Yang ${ }^{1}$ and Don D. Sin ${ }^{1,2}$

${ }^{1}$ Centre for Heart Lung Innovation, University of British Columbia, Vancouver, BC, Canada. ${ }^{2}$ Division of Respiratory Medicine, Dept of Medicine, St. Paul's Hospital, Vancouver, BC, Canada.

Correspondence: Don D. Sin, Division of Respiratory Medicine, Dept of Medicine, St. Paul's Hospital, 1081 Burrard Street, Vancouver, BC V6Z1Y6, Canada. E-mail: Don.Sin@hli.ubc.ca

Received: 18 April 2020 | Accepted after revision: 20 April 2020

Conflict of interest: J.M. Leung has nothing to disclose. C.X. Yang has nothing to disclose. D.D. Sin reports grants from Merck, personal fees for advisory board work from Sanofi-Aventis and Regeneron, grants and personal fees for lectures from Boehringer Ingelheim and AstraZeneca, personal fees for lectures and advisory board worm from Novartis, outside the submitted work.

\section{References}

1 Leung JM, Yang CX, Tam A, et al. ACE-2 expression in the small airway epithelia of smokers and COPD patients: implications for COVID-19. Eur Respir J 2020; 55: 2000688.

2 Garg S, Kim L, Whitaker M, et al. Hospitalization rates and characteristics of patients hospitalized with laboratory-confirmed coronavirus disease 2019-COVID-NET, 14 States, March 1-30, 2020. MMWR Morb Mortal Wkly Rep 2020; 69: 458-464.

3 Freedman R, Leonard S, Gault JM, et al. Linkage disequilibrium for schizophrenia at the chromosome 15q13-14 locus of the alpha7-nicotinic acetylcholine receptor subunit gene (CHRNA7). Am J Med Genet 2001; 105: 20-22.

4 Guan ZZ, Zhang X, Ravid R, et al. Decreased protein levels of nicotinic receptor subunits in the hippocampus and temporal cortex of patients with Alzheimer's disease. J Neurochem 2000; 74: 237-243.

5 Banerjee C, Nyengaard JR, Wevers A, et al. Cellular expression of alpha7 nicotinic acetylcholine receptor protein in the temporal cortex in Alzheimer's and Parkinson's disease-a stereological approach. Neurobiol Dis 2000; 7: 666-672.

6 Ramachandran Nair L, Liu X. Targeting the alpha4beta2- and alpha7-subtypes of nicotinic acetylcholine receptors for smoking cessation medication development. J Addict Res Ther 2019; 10: 381.

7 Panagis G, Kastellakis A, Spyraki C, et al. Effects of methyllycaconitine (MLA), an alpha 7 nicotinic receptor antagonist, on nicotine- and cocaine-induced potentiation of brain stimulation reward. Psychopharmacology (Berl) 2000; 149: 388-396.

8 Liang J, Tae HS, Xu X, et al. Dimerization of alpha-conotoxins as a strategy to enhance the inhibition of the human alpha7 and alpha9alpha10 nicotinic acetylcholine receptors. J Med Chem 2020; 63: 2974-2985. 